\title{
New strategies to ensure good patient-physician communication when treating adolescents and young adults with cancer: the proposed model of the Milan Youth Project
}

This article was published in the following Dove Press journal:

Clinical Oncology in Adolescents and Young Adults

24 August 2015

Number of times this article has been viewed

\author{
Maria Chiara Magni' \\ Laura Veneroni' \\ Carlo Alfredo Clerici \\ Tullio Proserpio ${ }^{3}$ \\ Giovanna Sironi' \\ Michela Casanova' \\ Stefano Chiaravalli' \\ Maura Massimino' \\ Andrea Ferrari
}

'Pediatric Oncology Unit, Fondazione IRCCS Istituto Nazionale Tumori, Milan, Italy; ${ }^{2}$ Department of Pathophysiology and Transplantation, University of Milan, Milan, Italy; ${ }^{3}$ Pastoral Care Unit, Fondazione IRCCS Istituto Nazionale Tumori, Milan, Italy

\section{Video abstract}

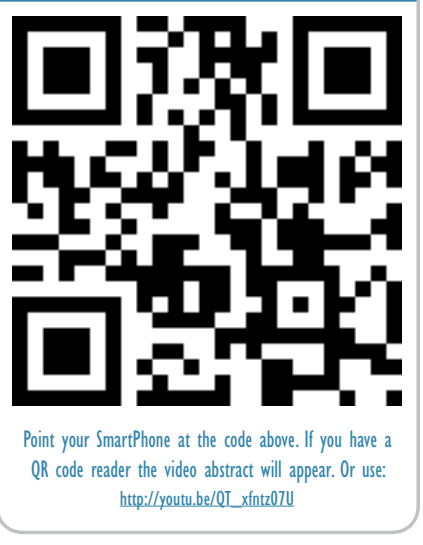

Correspondence: Andrea Ferrari Pediatric Oncology Unit, Fondazione IRCCS Istituto Nazionale Tumori, Via G Venezian, I-20I33 Milan, Italy Email andrea.ferrari@istitutotumori.mi.it
Abstract: Adolescence is a particularly complex time of life, entailing physiological, psychological, and social changes that further the individual's cognitive, emotional, and social growth. Being diagnosed with cancer at this time can have important consequences on an individual's emotional and physical development, and adolescent and young adult cancer patients have particular medical and psychosocial needs. Patient-physician communications are important in any clinical relationship, but fundamental in the oncological sphere because their quality can affect the patient-physician relationship, the therapeutic alliance, and patient compliance. A major challenge when dealing with adolescent and young adult patients lies in striking the right balance between their need and right to understand their disease, treatment, and prognosis, and the need for them to remain hopeful and to protect their emotional sensitivity. We herein describe the activities of the Youth Project of the Istituto Nazionale Tumori in Milan, Italy in order to share a possible model of interaction with these special patients and the tactics our group has identified to help them communicate and share their thoughts. This model implies not only the involvement of a multidisciplinary team, including psychologists and spirituality experts, but also the constitution of dedicated creative activities to give patients the opportunity to express feelings they would otherwise never feel at ease putting into words. These efforts seek the goal to minimize the potentially traumatic impact of disease on the patient's psychological well-being. Our group focused also on communication using modern media as vehicles of information, eg, integrating the use of social networks in the involvement of patients in adolescent- and young adult-dedicated activities and uploading informative videos on YouTube.

Keywords: relationship, teenagers, psychology, spirituality, art, social network

\section{Introduction}

Adolescence marks an individual's arrival at the crucially important crossroads between childhood and adulthood, when particular physiological, psychological, and social changes take place that lead to their cognitive, emotional, and social development. ${ }^{1,2}$ It is a highly complex time of life. Though all the changes involved are needed in order to enter adulthood, adolescents often worry about "losing themselves". 3 They are torn between their newfound desire for independence, and their lingering need for adults to care for them. ${ }^{3}$

Being diagnosed with cancer in this particular phase of an individual's development can have important emotional and physical consequences. Adolescent cancer patients need to be seen as special cases with particular medical and psychosocial needs. ${ }^{1,4,5}$ 
Oncologists should concern themselves with ensuring that young cancer patients maintain their social relations with their peers, nurture new relationships, and do not abandon the path toward independence while they are being treated. Their cancer should not be allowed to interfere with their development of their own, mature personality. ${ }^{6}$

\section{Patient-physician communication}

Patient-physician communication is hugely important in any clinical relationship, but even more so in the case of oncological patients because of the dramatic impact of their diagnosis and long-term treatment, which obliges patients to engage in long-lasting relations with their physicians. The quality of the information they are given, of the link that is established, and of the consequent patient-physician relationship will always affect the therapeutic alliance, patient compliance with proposed treatments, and the patients' and their families' satisfaction with the health services. ${ }^{7-9}$

By the end of the 1990s, it had been established that adult patients have the right to take part in the decisionmaking process concerning their treatment. Patients must be able to make a decision based on their full and adequate understanding of all the detailed information they receive from their care providers. ${ }^{10,11}$ As a rule, physicians do not question adults' capacity to make their own treatment-related decisions. ${ }^{12}$ When it comes to children, their participation in such decision-making processes will depend on their age and developmental level. The physician's communication methods have to be adapted to each child, ${ }^{12,13}$ who must be fully involved in deciding the treatment they should undergo. ${ }^{8,9}$

One of the greatest challenges when dealing with adolescent and young adult (AYA) patients lies in striking the right balance between their need and right to understand their disease, treatment, and prognosis, and the need to keep them hopeful and protect their emotional sensitivity. The International Society of Pediatric Oncology (SIOP) guidelines underscore the importance, when communicating with AYA cancer patients, of giving them information proportional to their age and maturity. ${ }^{8,14}$ In many countries, the lower limit for legal capacity is set at 18 years of age, beyond which patients must personally consent to any treatment they receive. Although an adolescent under 18 years is not legally entitled to accept or refuse a treatment, it is nonetheless crucial to ensure their understanding and obtain their assent. ${ }^{8,15}$ Like the SIOP, several international conventions - such as the United Nations' Convention on the Rights of the Child, ${ }^{16}$ the Convention on Human Rights and Biomedicine,${ }^{10}$ and the European Convention on the Exercise of
Children's Rights ${ }^{17}$ - impose respect for minors' rights within the health care system. These conventions establish the need to consult children and take their opinion into account during the decision-making process regarding their disease.

The SIOP has also been concerned with the psychosocial aspects of a cancer diagnosis in pediatric age. A Working Committee on Psychosocial Issues in Pediatric Oncology was formed by the SIOP after the SIOP first officially acknowledged the need to recognize the importance of psychosocial issues in the care and treatment of children with cancer in 1991. Over the years, the SIOP committee has worked on various issues and published numerous documents to promote psychosocial support intervention in pediatric oncology, and to integrate it in the model of care. ${ }^{8,9,14,18-25}$ Core aspects in the pediatric oncology setting concern: the need for a multidisciplinary team comprising different professionals coordinated by the pediatric oncologist; the establishment of a therapeutic alliance between the medical staff and the patient's family, which implies actively involving the latter in the patient's care; and focusing attention on the patient's needs. Communication with patients must be adequate and appropriate for their age and developmental level. ${ }^{14}$ Listening carefully to patients and obtaining their consent to treatments (consistent with their age and ability to understand) are essential to patient compliance, so patients should have an active role in making decisions that concern them. ${ }^{8}$

The pediatric oncology community has made more progress than other medical specialties in this field, having promptly recognized the importance of addressing new social and psychological needs within the patient-physician relationship. ${ }^{5}$ Compared with any other branch of medicine, and adult oncology in particular, pediatric oncology has certain features that have played an important part in focusing attention on these fundamental issues. First, the ratio of pediatric oncologists to patients in a typical pediatric oncology unit is generally higher than in an adult oncology department, and this makes it easier to establish stronger relationships with patients. Second, pediatric oncologists have always been more exposed than other specialists to patients' and their families' emotional issues, given the dramatic impact of a diagnosis of childhood cancer. Third, the patients' physiological growth is a major concern in the pediatric oncology setting, and any neoplastic disease and its treatment should be allowed to interfere as little as possible with the normal physical, emotional, and psychosocial development of patients of developmental age. ${ }^{6}$

After a consensus conference in 1997, the SIOP Working Committee on Psychosocial Issues in Pediatric Oncology 
stated that communicating a diagnosis should not be an isolated event in the patient-physician relationship. It should be the first of many steps in what is called a "communicative process and relationship" between the multidisciplinary health care team, patients, and their families. ${ }^{8,14} \mathrm{~A}$ diagnosis must be communicated in a manner that responds to patients' and their families' needs, and their different levels of prior knowledge and awareness, in order to gain the confidence of the parties involved. The guidelines were written with special reference to pediatric patients, but are also applicable to AYA cases.

The health care staff's open, honest communication with patients and families, and the latter's involvement in making clinical decisions, are considered extremely important to assuring a good compliance with the treatment. ${ }^{3,18,26}$ This is not always feasible, however, so it becomes important to make the model they use adaptable to different situations. It is also important to identify the most suitable setting in which to communicate and receive a cancer diagnosis: this should be a separate space, a quiet and comfortable room, ${ }^{14}$ where interruptions can be avoided; the encounter should be handled by the head of the pediatric oncology unit or a senior member of the medical staff, with the support of another member of the staff; and both the young patient's parents should be present. Other relatives, the family's local physician, or close friends may attend too, with the family's consent. Patients should take part in this meeting as well, adapting the setting to their age and level of development. It is fundamental to inform patients in an age-appropriate manner about their disease, the planned treatment, and the general prognosis. Information about the possibility of side effects, the duration of treatments, and the related pain and distress should not be omitted, otherwise patients might lose faith in their parents and the medical staff when they begin to experience these aspects. Most patients want to be clearly informed, and this is especially true in the case of AYAs. The information they demand often goes beyond the characteristics of the disease itself, also concerning whether they will be able to maintain the current lifestyle and routines. The specialists should explain the situation accurately to their patients and help them voice their questions and worries, demonstrating that they trust them and respect their rational and emotional concerns. A member of staff should also conduct a separate, private session with patients (especially in the case of teenagers and young adults), where the health care operator should elicit patients' questions and concerns about their disease and its treatment that they may not wish to share with their parents. The specialist should encourage them to talk openly and frankly with their families about the disease, its treatment, and their intellectual and emotional needs. ${ }^{9,27}$ All these steps are essential to enable patients and their families to feel at ease about asking the staff for support and help on a variety of issues, if necessary. ${ }^{14}$

The development of communication strategies dedicated to AYA with cancer still remains a challenge. In particular, it is difficult to propose and validate shared evidence-based guidelines. Similarly, up to now, the development of AYA cancer programs has been ad hoc rather than systematic, with no international guidelines nor methods to address all these issues typical of AYA patients. ${ }^{28}$ As the few existing AYAdedicated programs have not been systematically evaluated, it is not clear whether they impact upon determinants of health and health outcomes in this population. Recently, Tsangaris et al tried to address these issues using descriptive methods (qualitative interviews) while at the same time providing a systematic review of the literature. ${ }^{29}$ The authors stated that, amongst the most common needs expressed by AYA patients included in the study and in the analyzed literature, there are communication needs, together with social and service provision needs. Other research applies newly introduced scales, eg, the Parent-Adolescent Communication Scale and the Family Adaptability and Cohesion Evaluation Scale (FACES II), to evaluate communication between the AYA patient and their families. ${ }^{30}$ This study suggests that interventions to improve adolescent-parent communication could facilitate better family cohesion and ameliorate their psychological adjustment.

When developing age-specific models of care, care providers should always bear in mind that one of the main challenges for young people with cancer is to continue living as normally as possible, and to complete the developmental stages typical of their age. The rites of passage associated with adolescence should not be deferred because of the cancer and its treatment. $3,6,31$

The founding principle behind any model of care for clinicians dealing with AYA is that their patients are, first and foremost, young people - who just happen to have cancer. Clinicians should promote this sense of their normality in every aspect of their care. In 2010, Morgan et al wrote a review entitled "Sex, drugs, and rock ' $n$ ' roll: caring for adolescents and young adults with cancer" to describe the fundamental issues to consider when dealing with AYAs with cancer. ${ }^{6}$ To be able to have constructive conversations about such sensitive matters, it is imperative to establish an open relationship first. Of course, these issues need not be brought up when patients are first told about their diagnosis, 
but they cannot be neglected, and a frank discussion on these issues should be part of the communication process. It may be difficult for a young patient to talk about "sex" (sexual practices, sexual identity, and possible sexual dysfunctions) with a doctor, but it is essential to tell patients about the need to avoid sexually transmitted diseases, and to avoid pregnancies during their treatment. ${ }^{6}$ It is equally important to talk to patients about fertility, the risk of their fertility suffering as a result of their treatment, and the available fertility-preserving methods. ${ }^{3,32}$ A sensitive, nonjudgmental and non-paternalistic approach to "drugs" (alcohol and drug use and abuse) is also essential. Physicians are aware of the negative impact of alcohol and drugs on a patient's health, of their interactions with chemotherapies, and of the related psychosocial morbidity and risk of dependence. At the same time, they must remember that some alcohol and drug consumption may be part of an individual's physiological development at this age and have a particular role in peer group dynamics. To contain any problems of treatment compliance, care providers should deal flexibly with these issues, instead of taking a moralistic stance or imposing prohibitive rules that patients would be bound to disregard. 6 "Rock 'n' roll" refers to young people's lifestyle, perception of the world, and need to stretch the limits. It is important to help patients talk about their passions and their dreams for the future too.

\section{Informed consent process}

A particular aspect of patient-physician communication concerns the informed consent process, especially when dealing with young patients who have a poor prognosis and may be candidates for inclusion in experimental studies (Phase I and Phase II trials). Ensuring adherence to such treatments while helping patients to think as positively as possible and keeping them adequately informed demands a careful analysis of the methods used to communicate and deal generally with AYAs. This is a key issue for the involvement of patients with refractory and relapsing disease in experimental studies that are often likely to only be of any real benefit to future patients. Striking the right balance between informing adolescent patients about their disease, treatment, and prognosis and respecting their need to know the truth and to be fully aware of their condition while protecting their feelings and sustaining their hope at the same time may be extremely challenging. The informed consent process is a complex procedure that is completed in various stages, following strict guidelines, and it involves different aspects of communication and of the decision-making process. It has an important influence on the patient's psychological domain and on the biomedical issues involved in recruiting patients for the experimental protocols needed to improve treatments. For instance, the purpose of experimental Phase I studies is to establish the maximum dose of a drug that can be tolerated with an acceptable toxicity, and communicating this information is a challenge for physicians trying to involve families in such clinical trials. The whole issue becomes particularly complex when dealing with adolescents under 18 years of age, because they are not legally independent and they must be consulted together with their parents or a guardian legally responsible for them. Underage patients are entitled to be properly informed, and they have the faculty to sign to indicate their own consent, in addition to that of their legal representatives - and young patients may oppose the idea of being the object of such experimentation. Communication naturally cannot be reduced to the mere formality of obtaining a signature. We have to consider the advisability of telling patients that the drug they will be administered has no demonstrated efficacy and its potentially therapeutic effects have yet to be established. In the recent scientific literature, there is a paucity of studies on communication with oncological patients of developmental age involved in Phase I and Phase II protocols. ${ }^{33}$ There is no general consensus on the most appropriate minimum age, timing during the course of the disease, and terms to use for explicitly telling patients that their prognosis is poor and that the conventional therapeutic options are of no use. On the other hand, it is hard to imagine how a young patient might prefer to receive such information. Physicians should always focus on their patients' feelings. Doctors must be able to adapt their words to each patient's cognitive level. It is only by establishing a genuine relationship and understanding with their patients that physicians can address this task adequately, or at least try to do so.

\section{Spiritual aspects of care}

Teenagers typically wonder about the future and look for the meaning of life. ${ }^{34}$ These processes are already emotionally charged per se, raising doubts in young people's minds. But suffering and illness, and especially life-threatening diseases such as cancer, invariably interfere with their usual course. ${ }^{4}$ Giving patients and families the opportunity to talk about these issues is a crucial aspect of communication.

Religion and spirituality are topics that interest young patients with cancer. ${ }^{34,35}$ They are two different concepts: according to the National Cancer Institute, "religion" refers to precise beliefs and practices considered peculiar to a given form of worship, while "spirituality" is a more challenging concept to define. ${ }^{36}$ It is a concept existing in all cultures and 
considered a universal human capacity that may or may not be expressed in the form of a religious faith or practice. In fact, many atheists and agnostics may consider themselves spiritual individuals, though they are not religious. ${ }^{36,37}$ Spirituality covers different meaningful spiritual experiences, such as the search for a sense of inner peace and the meaning of life and death, in religious faith or along other paths. ${ }^{36,38}$

In a hospital ward, the person best qualified to deal with these topics is generally the hospital's chaplain. Regrettably, this figure is often associated with the idea of a patient's imminent death, and this prevents patients or their families from seeking the chaplain's support. In addition, patients, families, and even health care operators may not be aware that chaplains are trained to work with patients..$^{39,40}$

Given the depth and complexity of the spiritual sphere, we have acknowledged the need for a specialist, and that is why a priest has come to have an active role in the multidisciplinary team working at the Oncology Unit of the Istituto Nazionale Tumori, Milan, Italy. The chaplain is now a permanent staff member, and his role is mainly to sustain patients' need for religious faith (for those who are believers), to address patients' spiritual needs, and to help patients, family members, and health care operators to remain positive and hopeful. ${ }^{34,41,42}$ His role is fundamental in communications between staff and patients and/or their families. The chaplain on our multidisciplinary team is a Catholic priest specifically trained in counseling and working with people who are ill. He conducts general religious practices in hospital, such as celebrating mass and giving the sacraments at the request of patients and families. ${ }^{34}$ But, since 2011, his activities have been reorganized and better structured, and his work now includes daily ward visits, daily meetings with the psychologists on the staff, and weekly meetings with the medical personnel. During his daily rounds, the chaplain assesses patients' and any relatives' spiritual needs. He offers spiritual support to non-Catholic patients and families too, or, at the families' request, he calls in local representatives of other religions. The type of support he provides only partially overlaps with the work done by our psychologists, and it is available to patients throughout the time they are in our care, instead of being relegated to the end of the patient's life. Spiritual assistants should be seen as a fundamental part of the hospital staff, a source of spiritual support and a comforting presence in the ward, accompanying patients right from the early stages of their experience. It has been demonstrated that being able to count on the support of a chaplain who sustained their hope, comforted them, and responded to their spiritual needs had a positive impact on AYAs' attitudes to their disease. ${ }^{34,42}$
This model might apply to non-Catholic countries and cultures too. Recognizing the role of spirituality in AYA patients is, however, fundamental, regardless of their origin, faith, or culture. Therefore, addressing their spiritual needs with the help of a dedicated spiritual assistant who is part of the staff is fundamental in order for AYA patients to find meaning and gain acceptance of their cancer experience. It is worth mentioning that there are international guidelines for the training of chaplains (eg, the European Network of Health Care Chaplaincy) with the goal of addressing all patients' needs, regardless of their religion. Moreover, the Joint Commission International Accreditation Standards for Clinical Laboratories states that, given the need to safeguard patients' rights in the broadest possible sense, a modern hospital should have in place "a process to respond to patient and family's requests related to the patient's spiritual and religious beliefs". ${ }^{43}$ According to this view, the purpose of a spiritual assistant in the pediatric department should not be to convert individuals to a given belief system, but to respond to patients' spiritual needs and to provide comfort, thereby facilitating communication and relationships and preserving hope. ${ }^{34,39}$

\section{Communicating feelings to others: new strategies}

Even in a normal context, AYAs experience great difficulty in communicating their feelings, hopes, and fears, especially to adults. Adolescents tend to keep their private, intimate thoughts and feelings jealously to themselves in an effort to defend the emergence of their own individuality and identity against the constraints of the adult world. They try to prevent adults from gauging their innermost feelings. Under normal circumstances, this secretiveness can serve evolutionary goals, but it can become dangerous when adolescents keep frightening thoughts and negative emotions secret. Disease and treatments can incur painful changes in an individual's physical appearance and affect their relations with their peers and their future projects - and not voicing the feelings associated with these issues does not help adolescents to cope with them.

Sharing their emotions with someone else enables them to experience new thoughts and types of behavior and helps them to adjust. It is crucial for AYAs with cancer to be given the chance to express their emotions ${ }^{44}$ to health care professionals and to peers ${ }^{29}$ after their disease has been diagnosed, during treatment, and throughout follow-up. This helps them to manage their emotional response and cope with the psychological impact of their condition, ${ }^{6,18,45,46}$ in order to minimize the emotional burden of the disease. It also helps 
them avoid being overwhelmed by the disease and to absorb this experience as part of their own life history.

Psychologists can help, but only if the service they offer fulfills certain requirements. These specialists should not be seen as an emergency response, someone to call when something alarming happens, or when patients show symptoms of distress. They should be part of the team that accompanies adolescent patients from their diagnosis onward. Meeting a psychologist who is a daily presence in the ward, right from the very beginning of the course of their disease, gives teens the chance to engage with them and develop a relationship of trust and confidence, so that they can also talk about difficult things if they wish.

Since establishing adequate communications with patients can be so difficult, it is important to seek new strategies for making contact with them and letting them express themselves, as well as offering conventional psychological support. Innovative methods can prove very useful for communicating with AYAs. We have developed two main channels. First, we give patients the chance to express themselves during their treatment and follow-up by organizing ad hoc activities based on art and creative spirit as part of our Youth Project. Second, we have begun to consider the role of the Internet and social networks in our AYA patients' community, with a view to filling the gap in the information available on the Web and to creating a new platform for communicating with patients.

The Youth Project at the Pediatric Oncology Unit of the Istituto Nazionale Tumori in Milan, Italy is dedicated to adolescents (over 15 years old) and young adults (up to 25 years old) with pediatric solid tumors. Although such patients access the same facilities and are managed by the same staff as our pediatric patients, they are also offered some dedicated services ${ }^{47}$ The Youth Project was founded in 2011 to develop a model of care for AYA patients based on a change of cultural and organizational approach to their treatment. It has two main goals: to improve clinical aspects of
AYA patient care (eg, by increasing their involvement in international clinical trials, supporting scientific research in this area, providing psychosocial support and fertilitypreserving facilities); and to design activities tailored to their needs. As a result, the Pediatric Oncology Unit now has dedicated multifunctional spaces to AYA patients (a leisure room, a classroom, and a gym where patients can work out with two personal trainers), where these patients engage in structured creative activities supported by professionals.

\section{Communicating through art}

Creative activities have proved a very effective way to help patients express feelings, thoughts, and fears they would otherwise never have the chance or the courage to put into words. In the dramatic experience of cancer, releasing emotions is crucial to minimizing the potentially traumatic impact of the disease on the patient's psychological well-being. Art thus becomes a vehicle that enables patients to share their emotions freely without being asked explicitly to do so, thus relieving their psychological burden. They are given a chance to tell their story and to be heard.

Our first project (completed in 2012) focused on fashion. Over a period of 6 months, patients designed a fashion collection with their own brand and logo (B. Live), then they presented their collection at a proper fashion show. The project was coordinated by a professional fashion designer, Gentucca Bini, and other professionals were involved (a photographer, a fashion journalist, and a makeup artist). Twenty-four patients aged 15-20 years took part in the project (18 of them while receiving treatment, the remainder during their follow-up). They met in hospital twice a month, for at least 2 hours each time. Beginning with a review of the fashion iconography of the last 30 years, they studied designs and analyzed the images used in advertising, films, fashion magazines, and cartoons. Then, they chose the colors, patterns, fabrics, and accessories they wanted to use (Figure 1).
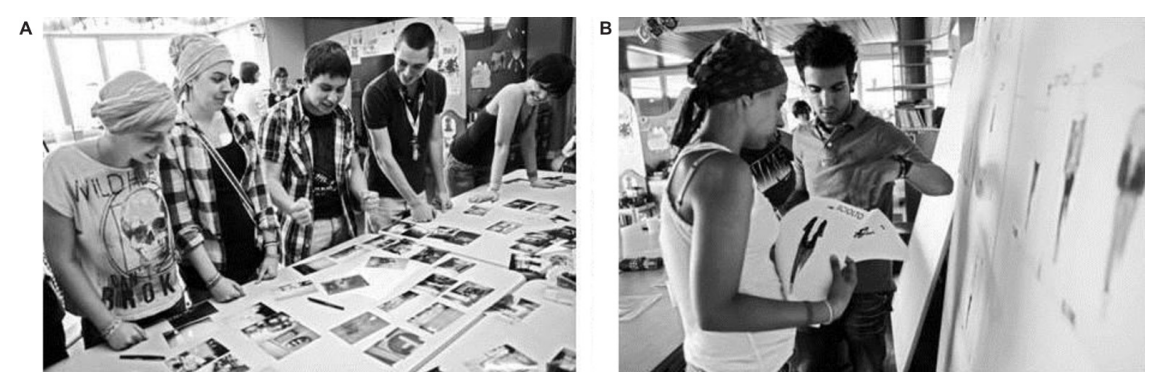

Figure I (A) Patients met in hospital twice a month in the multifunctional room in the Pediatric Department (Istituto Nazionale Tumori, Milan, Italy) to prepare the fashion collection. (B) Patients at work, studying apparel models, and choosing colors, patterns, and fabrics.

Note: Photographs courtesy of Laura Larmo. 
A private, password-protected group on Facebook was created so that patients unable to attend the meetings could stay in touch, and this also enabled patients to work together on the project in between meetings. The project helped the AYA patients to feel they were part of a group sharing the same kinds of problems and made them feel better able to cope with their cancer. Being involved in creating something beautiful while in hospital - an environment previously experienced only as a place of suffering, anxiety, and fear-helped them to feel more at ease about coming to appointments. Some of our patients said the project and the relations it enabled them to develop with peers and doctors supported their hopes better than anything else. ${ }^{28,48}$ At a time when they were experiencing a loss of control over their own bodies and physical appearance, designing their own personal style of clothing could restore a sense of some degree of control over the changes they were undergoing (Table 1). The fashion project integrated the usual forms of psychological support offered to patients, serving as a special form of expression during the course of their treatment.

The second project was implemented in 2013 and focused on music. This form of expression has a very important role in every adolescent's life, as it can put what young people experience into words, speak of their search for love and the meaning of life, or the need to stretch the limits. Here again, the project was coordinated by professionals - the bass guitarist

Table I The fashion project gave our adolescent and young adult patients a novel way to express themselves; here are some of their comments

Valeria (I5-year-old, affected by soft tissue sarcoma)

Federica (16-year-old, Ewing sarcoma)

Eleonora (17-year-old, osteosarcoma)

Alessandro (16-year-old, Hodgkin lymphoma)

Elisa (16-year-old, Ewing sarcoma)

Gabriele (19-year-old, brainstem tumor)

Note: Quotes from Veneroni et al. ${ }^{4}$ of a famous Italian rock band (Faso, from Elio e le Storie Tese) and a vocalist, Paola Folli - who helped our patients write their story in music, in a song called "Clouds of Oxygen". Twenty patients from 15 to 25 years old took part in the project, which took 8 months to complete and was organized along the same lines as the previous year's fashion project. The song's lyrics emerged from a jumble of phrases, images, memories, hopes, and fears contributed by the patients. The melodies came from scraps of tunes and brief sequences of notes written or sung by the teenagers, but also hospital sounds like the rhythmic hum of the chemotherapy pump and the nurses' buzzer, all pieced together by the professional musician (Figure 2).

The Journal of Clinical Oncology published the story of the song ${ }^{49}$ and the adolescents' comments on the meaning of the lyrics, which spoke of their feelings, difficulties, and expectations - and that publication is proof in itself that the oncology community recognizes the importance of coping with the complex psychological world of teenagers with cancer by developing dedicated projects and novel methods for communicating with their inner world.

\section{Internet and social networks}

Since engaging in these specific projects, we have begun to consider the role of the Internet in our AYA patient community. The advent and diffusion of the Internet, and of social networks in particular, has contributed to revolutionizing the way people communicate. When dealing with AYA, we should never forget the role of the Web in their lives, and especially of Facebook (a social network with more than a billion active users over 13 years old). Using Facebook has its pros and cons. It poses some risks that are reason for concern among health care professionals, but it can also be a powerful resource ${ }^{50}$ Clinicians using a personal Facebook profile to communicate with patients must take care because it has been demonstrated that their self-disclosures may diminish their patient's satisfaction and trust. ${ }^{51}$ It can also lead to a sense of intimacy that distorts the established patient-clinician roles. Some patients or families may feel free to ask for the clinician's advice or opinion outside the institutional communication channels, not only creating embarrassment but also raising important medicolegal issues. ${ }^{52}$ Relationships between patients have also been affected by the diffusion of Facebook. Social networks enable patients to stay constantly up to date on each other's state of health, and the pervasiveness of such messages can overwhelm an individual's legitimate preference not to know about other patients failing to respond to treatments or dying. Such information can make patients lose hope and fear that it will be their turn next. 


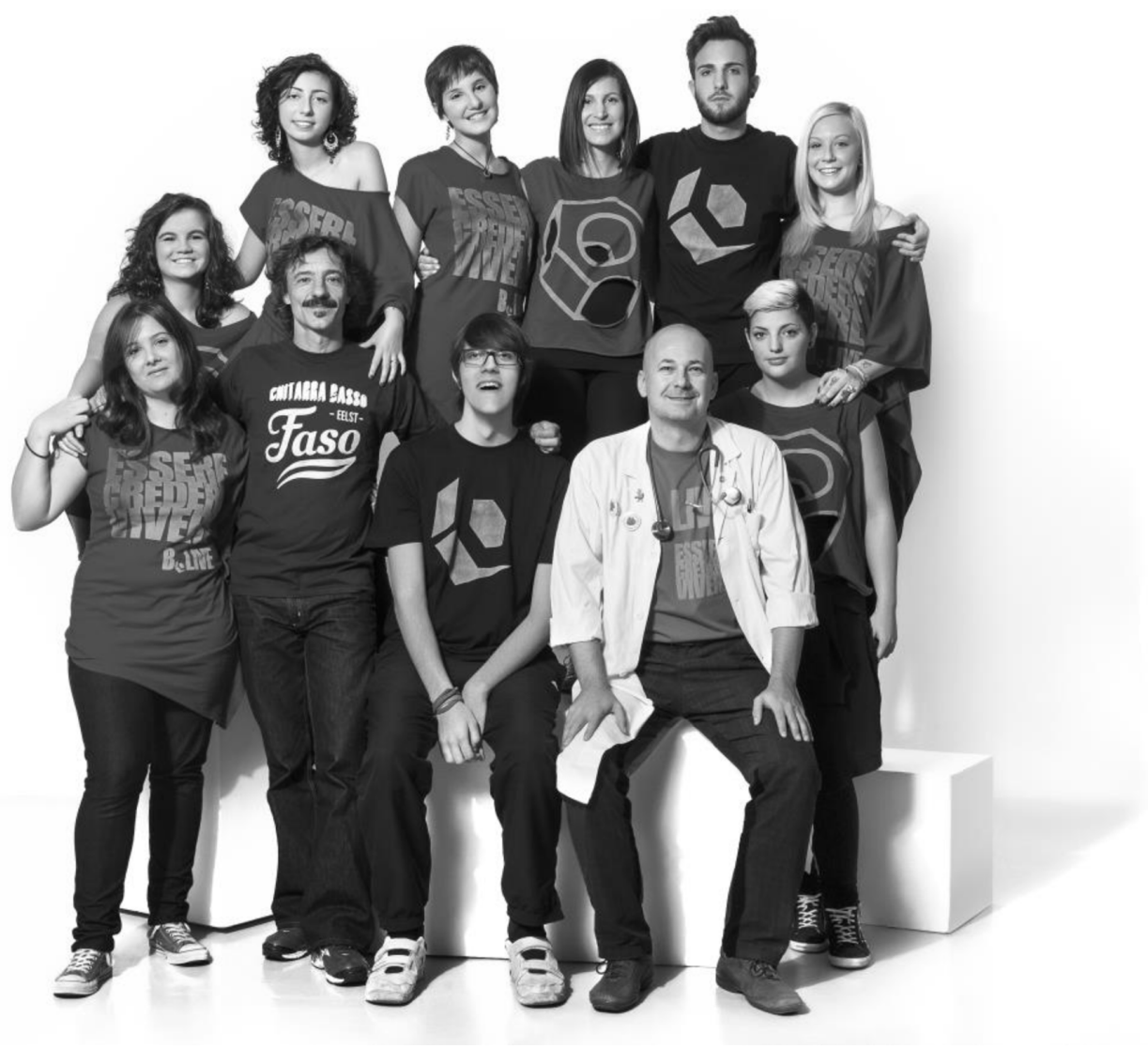

Figure 2 Music as a means of communication with and among adolescents taking part in the Youth Project at the Istituto Nazionale Tumori in Milan, Italy. Notes: With help from a famous Italian rock band (Elio e Le Storie Tese), patients wrote a song called "Clouds of Oxygen". The picture shows some of the patients posing for the photographer with one of the doctors. Photograph courtesy of Matteo Volta.

Alongside these controversial aspects, it is imperative not to forget the positive side of social networking. First, there is the previously mentioned opportunity for patients to work together on a project even when they cannot physically be in the same place. Facebook helps patients to form peer groups, an essential way for AYA patients to find support ${ }^{44}$ because it brings them into contact with others who understand them and share the same feelings. ${ }^{28,46}$ Patients can also maintain their social relations with friends at home, and thus feel less isolated while in hospital. This helps them not to feel eradicated from their social background, which is crucially important to their well-being and physiological development. They can stay in touch with classmates, swap notes, and try to keep up with their school lessons, feeling more integrated with their group at school. ${ }^{50}$ For all these reasons, social networks cannot be ignored when dealing with AYA patients, but it is essential to find the best way to integrate them in the work of the health care staff, leveraging on the positive aspects and creating strict guidelines with which all operators must comply.

Our interest in the Internet should not be limited to the use of Facebook, however. Previous studies have shown that AYAs are diagnosed with a significant symptom delay by comparison with younger children. ${ }^{53,54}$ Not only AYAs and their families, but also other specialists, seem to be scarcely aware of the possibility of this age group developing cancer, ${ }^{54}$ hence our intention to improve awareness by using the media that young people use most in their normal everyday life. Video-sharing sites have become increasingly important in recent years in providing information and orienting people's decisions relating to their health, and adolescents and their families use the Internet to find information about oncological diseases.

Browsing the Internet, we found a real knowledge gap on the topic of cancer in adolescence; there was little or even false information available. In a study on the availability and type and origin of video content on YouTube relating to a particular set of pediatric neoplastic diseases (rhabdomyosarcoma and soft tissue sarcomas), we identified 149 videos, only 25 of them judged to be useful; only one was produced by a doctor, while 123 were produced by patients or families, often to commemorate a patient who died. ${ }^{55}$ To fill this gap, we shot some informative videos about the main pediatric cancer diseases, ${ }^{55,56}$ uploaded them on YouTube, and added them 
to the Youth Project website archive under the link http:// www.ilprogettogiovani.it/index.php/iprogettispeciali/2-noncategorizzato/65-nuvole. We also prepared a video (see https:// www.youtube.com/watch? $\mathrm{V}=\mathrm{ZELw} \mathrm{II} 7 \mathrm{fdPw}$ ) wherein some of the patients we treated talk about their experience. In the spirit of peer support, they talk about their symptoms and how they felt when they were told their diagnosis and administered their treatments, and afterward when they returned to normal life. Hearing these patients talk about their experiences is useful for other young people in the same predicament, and also for the staff who treat them and for those who allocate resources and organize services and spaces in the hospitals where they are treated. It is important to give "voice and choice" to AYA patients in the process of developing services tailored to their needs. The initiatives developed within the Youth Project may therefore represent a possible model to improve the challenge of the patient-physician relationship and communication with people in this peculiar age range. Currently, there is no evidence that such strategies effectively work, and further validation is needed. However, applying rigorous methodological research designs to such projects may be very difficult, if not impossible, as we cannot randomize our patients' participation to the different projects held. Quantitative analyses are extremely difficult to apply to these issues, and a single local project will unlikely demonstrate the effectiveness of a proposed model. Possible matters to analyze may be: the growth of the number of AYA patients seen at a single institution; the percentage of AYA patients enrolled in clinical trials; the percentage of AYA patients receiving fertility preservation, or teaching support; the number of publications or grants on AYA projects; and the community and media recognition. More focus on the psychosocial and communication projects and patient (or provider) satisfaction may be a possible goal, and specific surveys and quality-of-life measurements are ongoing.

\section{Conclusion}

Patient-physician communication poses a huge challenge for physicians dealing with AYA cancer patients. It is important to meet patients' needs and to devise tactics to help them communicate freely with us and thereby contain the psychological burden of their situation. Modern communication media should not be ignored when dealing with adolescents, partly because they can be helpful, and partly because otherwise they may be a source of misinformation. It is important for health care operators to play a part in social networks and the Internet, based on established behavioral guidelines.

\section{Acknowledgments}

The authors thank the Associazione Bianca Garavaglia for supporting the Youth Project at the Pediatric Oncology Unit at the Istituto Nazionale Tumori in Milan, Italy, and the Magica Cleme Foundation for supporting some of the described initiatives. The patients gave consent for their likenesses to be published in the video abstract, and in Figures 1 and 2 of this paper.

\section{Disclosure}

The authors report no conflicts of interest in this work.

\section{References}

1. Bleyer A, Budd T, Montello M. Adolescents and young adults with cancer: the scope of the problem and criticality of clinical trials. Cancer. 2006;107(7 Suppl):1645-1655.

2. Developing Adolescents: A Reference for Professionals. Washington: American Psychological Association; 2002. Available from: http:// www.apa.org/pi/families/resources/develop.pdf. Accessed February 27, 2015.

3. Abrams AN, Hazen EP, Penson RT. Psychosocial issues in adolescents with cancer. Cancer Treat Rev. 2007;33(7):622-630.

4. Zebrack B, Isaacson S. Psychosocial care of adolescent and young adult patients with cancer and survivors. J Clin Oncol. 2012;30: 1221-1226.

5. Epelman CL. The adolescent and young adult with cancer: state of the art - psychosocial aspects. Curr Oncol Rep. 2013;15:325-331.

6. Morgan S, Davies S, Palmer S, Plaster M. Sex, drugs, and rock 'n' roll: caring for adolescents and young adults with cancer. J Clin Oncol. 2010;28(32):4825-4830.

7. Veneroni L, Ferrari A, Massimino M, Clerici CA. [Facebook in oncology. Review of the literature]. Recenti Prog Med. 2015;106:46-51. Italian.

8. Spinetta JJ, Masera G, Jankovic M, et al; SIOP Working Committee on psychosocial issues in pediatric oncology. Valid informed consent and participative decision-making in children with cancer and their parents: a report of the SIOP Working Committee on psychosocial issues in pediatric oncology. Med Pediatr Oncol. 2003;40(4): 244-246.

9. Masera G, Spinetta JJ, Jankovic M, et al. Guidelines for a therapeutic alliance between families and staff: a report of the SIOP Working Committee on Psychosocial Issues in Pediatric Oncology. Med Pediatr Oncol. 1998;30(3):183-186.

10. Convention for the Protection of Human Rights and Dignity of the Human Being with regard to the Application of Biology and Medicine: Convention on Human Rights and Biomedicine [webpage on the Internet]. April 4, 1997; Oviedo, Asturias. Strasbourg: Council of Europe [cited March 1, 2015]. Available from: http://conventions.coe. int/Treaty/en/Treaties/Html/164.htm. Accessed April 4, 2015.

11. Syse A. Norway: valid (as opposed to informed) consent. Lancet. 2000;356(9238):1347-1348.

12. Blustein J, Moreno JD. Valid consent to treatment and the unsupervised adolescent. In: Blustein J, Levine C, Dubler NN, editors. The Adolescent Alone: Decision Making in Health Care in the United States. Cambridge: Cambridge University Press; 1999:100-110.

13. Bragadóttir H. Children's rights in clinical research. J Nurs Scholarsh. 2002;32:179-184.

14. Masera G, Chesler MA, Jankovic M, et al. SIOP Working Committee on psychosocial issues in pediatric oncology: guidelines for communication of the diagnosis. Med Pediatr Oncol. 1997;28:382-385.

15. Masera G. Il doppio consenso e una legge morale [The double consent and a moral law]. Pediatria. 2002;10:5-6. Italian. 
16. Convention on the Rights of the Child [webpage on the Internet]. November 20, 1989; New York. Geneva: Office of the United Nations High Commissioner for Human Rights (OHCHR) [cited March 1, 2015]. Available from: http://www.ohchr.org/en/professionalinterest/ pages/crc.aspx. Accessed April 4, 2015.

17. European Convention on the Exercise of Children's Rights [webpage on the Internet]. January 25, 1996; Strasbourg. Strasbourg: Council of Europe [cited March 1, 2015]. Available from: http://conventions.coe. int/Treaty/en/Treaties/Html/160.htm. Accessed April 4, 2015.

18. Spinetta JJ, Masera G, Eden T, et al. Refusal, non-compliance, and abandonment of treatment in children and adolescents with cancer: a report of the SIOP Working Committee on Psychosocial Issues in Pediatric Oncology. Med Pediatr Oncol. 2002;38:114-117.

19. Masera G, Spinetta JJ, D’Angio GJ, et al. SIOP working committee on psychosocial issues in pediatric oncology. Critical commentary. Med Pediatr Oncol. 1993;21:627-628.

20. Masera G, Jankovic M, Deasy-Spinetta P, et al. SIOP Working Committee on Psychosocial Issues in Pediatric Oncology: guidelines for school/education. Med Pediatr Oncol. 1995;25(6):429-430.

21. Masera G, Chesler M, Jankovic M, et al. SIOP Working Committee on Psychosocial issues in pediatric oncology: guidelines for care of long-term survivors. Med Pediatr Oncol. 1996;27(1):1-2.

22. Spinetta JJ, Jankovic M, Eden T, et al. Guidelines for assistance to siblings of children with cancer: report of the SIOP Working Committee on Psychosocial Issues in Pediatric Oncology. Med Pediatr Oncol. 1999;33(4):395-398.

23. Masera G, Spinetta JJ, Jankovic M, et al. Guidelines for assistance to terminally ill children with cancer: a report of the SIOP Working Committee on psychosocial issues in pediatric oncology. Med Pediatr Oncol. 1999;32(1):44-48.

24. Spinetta JJ, Jankovic M, Ben Arush MW, et al. Guidelines for the recognition, prevention, and remediation of burnout in health care professionals participating in the care of children with cancer: report of the SIOP Working Committee on Psychosocial Issues in Pediatric Oncology. Med Pediatr Oncol. 2000;35(2):122-125.

25. Jankovic M, Spinetta JJ, Martins AG, et al; SIOP Working Committee on Psychosocial Issues in Pediatric Oncology. Non-conventional therapies in childhood cancer: guidelines for distinguishing non-harmful from harmful therapies: a report of the SIOP Working Committee on Psychosocial Issues in Pediatric Oncology. Pediatr Blood Cancer. 2004;42(1):106-108.

26. Barr RD. On cancer control and the adolescent. Med Pediatr Oncol. 1999;32:404-410.

27. Jankovic M, Loiacono NB, Spinetta JJ, Riva L, Conter V, Masera G. Telling young children with leukemia their diagnosis: the flower garden as analogy. Pediatr Hematol Oncol. 1994;11(1):75-81.

28. Ferrari A, Thomas D, Franklin AR, et al. Starting an adolescent and young adult program: some success stories and some obstacles to overcome. J Clin Oncol. 2010;28(32):4850-4857.

29. Tsangaris E, Johnson J, Taylor R, et al. Identifying the supportive care needs of adolescent and young adult survivors of cancer: a qualitative analysis and systematic literature review. Support Care Cancer. 2014;22(4):947-959.

30. Phillips-Salimi CR, Robb SL, Monahan PO, Dossey A, Haase JE. Perceptions of communication, family adaptability and cohesion: a comparison of adolescents newly diagnosed with cancer and their parents. Int J Adolesc Med Health. 2014;26(1):19-26.

31. D'Agostino NM, Penney A, Zebrack B. Providing developmentally appropriate psychosocial care to adolescent and young adult cancer survivors. Cancer. 2011;117(10 Suppl):2329-2334.

32. Ferrari A, Veneroni L, Clerici CA, et al. [Adolescents with cancer: the "Youth Project" at the Istituto Nazionale Tumori in Milan]. Recenti Prog Med. 2013;104:10-16. Italian.

33. Baker JN, Leek AC, Salas HS, et al. Suggestions from adolescents, young adults, and parents for improving informed consent in phase 1 pediatric oncology trials. Cancer. 2013;119(23):4154-4161.

34. Proserpio T, Ferrari A, Veneroni L, Giacon B, Massimino M, Clerici CA. Spiritual aspects of care for adolescents with cancer. Tumori. 2014;100(4):130e-135e.
35. Juvakka T, Kylmä J. Hope in adolescents with cancer. Eur J Oncol Nurs. 2009;13:193-199.

36. Spirituality in Cancer Care-for health professionals $\left(\mathrm{PDQ}^{\circledR}\right)$ [webpage on the Internet]. Bethesda: National Cancer Institute [updated July 3, 2014; cited March 18, 2015]. Available from: http://www.cancer.gov/ cancertopics/pdq/supportivecare/spirituality/HealthProfessional. Accessed April 4, 2015.

37. Astrow AB, Wexler A, Texeira K, He MK, Sulmasy DP. Is failure to meet spiritual needs associated with cancer patients' perceptions of quality of care and their satisfaction with care? J Clin Oncol. 2007;25(36): $5753-5757$.

38. Task Force report: spirituality, cultural issues, and end of life care. In: Association of American Medical Colleges: Report III. Contemporary Issues in Medicine: Communication in Medicine. Washington: Association of American Medical Colleges; 1999:24-29.

39. Proserpio T, Piccinelli C, Clerici CA. Pastoral care in hospitals: a literature review. Tumori. 2011;97:666-671.

40. Fitchett G, Lyndes KA, Cadge W, Berlinger N, Flanagan E, Misasi J. The role of professional chaplains on pediatric palliative care teams: perspectives from physicians and chaplains. J Palliat Med. 2011;14: 704-707.

41. What Is Spiritual Care? [webpage on the Internet]. Baltimore, MD: University of Maryland Medical Center [updated April 30, 2013; cited March 18, 2015]. Available from: http://umm.edu/patients/pastoral/ what-is-spiritual-care. Accessed April 4, 2015.

42. Proserpio T, Ferrari A, Lo Vullo S, et al. Hope in cancer patients: the relational domain as a crucial factor. Tumori. Epub May 23, 2015.

43. Joint Commission International Accreditation Standards for Clinical Laboratories. 2nd ed. Oak Brook, IL; Joint Commission International; 2009.

44. Marris S, Morgan S, Stark D. 'Listening to Patients': what is the value of age-appropriate care to teenagers and young adults with cancer? Eur J Cancer Care (Engl). 2011;20(2):145-151.

45. Clerici CA, Massimino M, Casanova M, et al. Psychosocial referral and consultation for adolescents and young adults with cancer treated at a pediatric oncology unit. Pediatr Blood Cancer. 2008;51:105-109.

46. Zebrack BJ. Psychological, social, and behavioral issues for young adults with cancer. Cancer. 2011;117(10 Suppl):2289-2294.

47. Ferrari A, Clerici CA, Casanova M, et al. The Youth Project at the Istituto Nazionale Tumori in Milan. Tumori. 2012;98:399-407.

48. Veneroni L, Clerici CA, Proserpio T, et al. Creating beauty: the experience of a fashion collection prepared by adolescent patients at a pediatric oncology unit. Tumori. Epub May 23, 2015.

49. Ferrari A, Veneroni L, Clerici CA, et al. Clouds of oxygen: adolescents with cancer tell their story in music. J Clin Oncol. 2015;33(2): $218-221$.

50. O'Keeffe GS, Clarke-Pearson K; Council on Communications and Media. The impact of social media on children, adolescents, and families. Pediatrics. 2011;127:800-804.

51. Beach MC, Roter D, Rubin H, Frankel R, Levinson W, Ford DE. Is physician self-disclosure related to patient evaluation of office visits? J Gen Intern Med. 2004;19:905-910.

52. Dizon DS, Graham D, Thomson MA, et al. Practical guidance: the use of social media in oncology practice. J Oncol Pract. 2012;8:e114-e124.

53. Ferrari A, Miceli R, Casanova M, et al. The symptom interval in children and adolescents with soft tissue sarcomas. Cancer. 2010;116(1): $177-183$.

54. Veneroni L, Mariani L, Lo Vullo SL, et al. Symptom interval in pediatric patients with solid tumors: adolescents are at greater risk of late diagnosis. Pediatr Blood Cancer. 2013;60(4):605-610.

55. Clerici CA, Veneroni L, Bisogno G, Trapuzzano A, Ferrari A. Videos on rhabdomyosarcoma on YouTube: an example of the availability of information on pediatric tumors on the web. J Pediatr Hematol Oncol. 2012;34(8):e329-e331.

56. Veneroni L, Ferrari A, Carraro M, Clerici CA. Video online e medicina; nuove tecnologie per clinici e pazienti [Online videos and medicine; new technologies for clinicians and patients]. Recenti Prog Med. 2012;103: 177-182. Italian. 
Clinical Oncology in Adolescents and Young Adults

Dovepress

\section{Publish your work in this journal}

Clinical Oncology in Adolescents and Young Adults is an international, peer-reviewed, open access journal publishing original research, reports, editorials, reviews and commentaries on all aspects of epidemiology, diagnosis and treatment of cancers in adolescents and young adults. The manuscript management system is completely online and includes a very quick and fair peer-review system. Visit http://www.dovepress.com/testimonials.php to read real quotes from published authors.

Submit your manuscript here: http://www.dovepress.com/clinical-oncology-in-adolescents-and-young-adults-journal 